\title{
RATIONALISM AND EMPIRICISM IN MODERN MEDICINE
}

\author{
WARREN NEWTON*
}

I

\section{INTRODUCTION}

About ten years ago, after fellowships and clinical experience in a community setting, I had my first experience as a ward attending in a university hospital. ${ }^{1}$ We were working with cardiac patients, and I was struck by the common treatment each patient received. No matter what the symptoms, patients received an exercise treadmill, an echocardiogram, and were put on a calcium channel blocker. ${ }^{2}$ This was remarkable at the time because there were in excess of thirty randomized controlled trials showing the benefit of beta-blockers, a different class of medicines, to treat patients following a heart attack. Indeed, by 1990 , there was initial evidence that calcium channel blockers not only failed to improve outcomes, but actually made them worse.

The point is not to criticize the medical culture at that hospital-similar examples can be found at every medical center-but rather to explore why there was so much fondness for calcium channel blockers. One factor was the substantial drug company support of faculty research on silent myocardial ischemia. Another factor was what might be called medical fashion. The most likely explanation, however, was more fundamental. For my cardiology colleagues, it was biologically plausible that calcium channel blockers were better than betablockers. Like beta-blockers, calcium channel blockers reduce heart rate and myocardial wall stress, but they lack the side effects of beta-blockers. In other words, what was important to my colleagues was not the outcome of the critical trials, but our understanding of the mechanisms of disease.

This is an example of the tension between rationalism and empiricism in medicine. Rationalism is the search for and emphasis on basic mechanisms of disease, which then color all clinical decisions. Empiricism is defined as the emphasis on the outcomes of individual patients and groups of patients. My

Copyright (C) 2001 by Warren Newton

This article is also available at http://www.law.duke.edu/journals/64LCPNewton.

* Associate Professor, Department of Family Medicine, University of North Carolina, Chapel Hill.

Thanks go to Beat Steiner, M.D., Katrina Donahue, M.D., Remy Coeytaux, M.D., and Allen Daugird, M.D., M.B.A., all at the Department of Family Medicine at the University of North Carolina, for their comments on this paper. Any remaining errors are mine.

1. Figure 1 in the Appendix summarizes our experience with cardiac patients; each line represents one or more patients.

2. Calcium channel blockers describes a particular class of medicines. 
thesis is that there is an ongoing and fundamental tension between these two different ways of thinking. While these ways of thinking can be complementary, the tension persists, exploding around specific clinical and legal controversies. Understanding the tension between rationalism and empiricism provides important background in considering the role of expert advice.

Part II of this article explores the roots of rationalism and empiricism in the Hippocratic tradition. Using the Flexner report as a text, Part III emphasizes the triumph of the rationalists in the founding of modern medicine. Part IV briefly describes the development of clinical epidemiology and the evidencebased medicine over the last thirty years. Part VI attempts to explicate how this tension illuminates fundamental clinical and policy questions that doctors, the health care system, and the legal system confront today. My goal is not to present a detailed explication of the epistemology of medical science, but rather an intellectual history ${ }^{3}$ sketching out what has animated the thinking of clinicians.

\section{II}

\section{HIPPOCRATIC ROOTS}

The Hippocratic tradition rests on many authors, not just the historical Hippocrates of Cos, but a plethora of later writers through antiquity, from Greece to Alexandria to Rome. This article focuses on two major sects of that tradition that dominated in Alexandria from the fourth century B.C. through Roman times. $^{4}$ The dominant medical influence in the classical age was rationalism. Tracing its origin from Thessalos and Drakan, the sons of Hippocrates, rationalism is the oldest of the sects. Thessalos and Drakans emphasized the importance of natural philosophy in medicine, believing that "where observation failed, reason might surprise." "humours" as first taught by Pythagoras:

The body of man has in itself blood, phlegm, yellow bile, and black bile: . . [N]ow he enjoys the most perfect health when those elements are duly proportioned to one another in respect of compounding power and bulk and when they are perfectly mingled. Pain is felt when one of these elements is in defect or excess or is isolated in the body without being compounded with all the others.

Thus, health was seen as the proper mixture of humours and disease was an imbalance. Most medical writing dealt with disputes about the nature of the humours, what the substances were, and how the balance of humours was altered by flow and constriction. From the perspective of the development of modern

3. See generally Franklin L. BAUMER, MOdERn EuropeAn THOUght: CONTINUITY AND CHANGE IN IDEAS 1600-1950 (1977).

4. It is difficult to access the thinking of the classical Greek authors. In addition to the linguistic and cultural barriers, many of the original texts were lost in the fire at Alexandria, and what we know is through later commentators. See, e.g., RALPH H. MAJOR, A History OF MEDICINE (1954); PliniO Prioreschi, A History of Medicine (2d ed. 1996); Wesley D. Smith, The Hippocratic TRADITION (1997).

5. See MAJOR, supra note 4, at 150.

6. Id. at 123 . 
ideas about medicine, this interest is important primarily because it motivated the first focused research in human anatomy in Alexandria in the third and second century B.C.

For the purposes of my argument, however, it should be stressed that the focus was on how disease develops or, in modern parlance, on mechanisms of disease. This emphasis became a lens through which all of clinical medicine was seen. Medical advances were understood to come from deductions concerning physiology, and the clinical implications were derived directly from the understanding of the humours. Thus, diagnosis was the recognition of the current balance of the humours, and a disease resulting from an excess of a particular humour might be treated with a procedure or a substance that depleted that humour. There was a tendency to think of disease as having a single cause: a specific disbalance of the humours. Prognosis was relatively less important than other clinical questions.

The empiricists were a splinter group that detached itself from the rationalists in the later part of the third century B.C. They rose in protest against the dried formalization of the rationalist school and in response to the anatomic discoveries. These discoveries, while brilliant, had contributed little to healing the sick. Furthermore, there was concern about the ethics of the dissection, and particularly the vivisection, practiced by the anatomists of that era. The empiricists rejected abstractions and general medical theories in favor of observation. They based their practice on the recollection of past observations and the knowledge of how similar symptoms had developed, what their outcomes were, and the determination of similarity between the case at hand and previous cases. As Celsus, a later Roman writer, argued,

if theoretical reasoning would have been sufficient, philosophers would be the best physicians .... Often the cause of disease is known as, for example, in cases of injuries or wounds, but this does not help in the treatment. As the cause of disease is uncertain and incomprehensible, we should rely on ... what experience has taught us. ${ }^{8}$

Authority was a target, "since neither the philosophers nor the physicians can agree among themselves, therefore one's reliance should be placed on no man's argument, on no man's authority."

To the empiricists, disease was not an entity but a group of systems, each of which required treatment. Experience was their lodestar: As Celsus later framed it, it is not how we digest, but what is digestible that matters. ${ }^{10}$ As a consequence, the main interest of empiricists lay in therapeutics more than in mechanisms of disease. Pharmacology and surgery were their preferred means to treat disease, and their writings are dominated by discussions of specific symptoms, remedies, similarities, and outcomes. The emphasis on therapy had an impact on how other kinds of clinical questions were addressed. The empiri-

\footnotetext{
7. See PRIORESCHI, supra note 4 , at $474-563$.

8. Id. at 547 .

9. See id.

10. See MAJOR, supra note 4, at 151.
} 
cists did not value looking for the "prime causes" of diseases. Diagnosis emphasized the recognition of discrete symptoms. In contrast to the rationalists, the empiricists believed that outcomes was the most important issue, with prognosis as a secondary focus.

III

\section{FLEXNER AT THE FOUNDING OF MODERN MEDICINE}

What we understand as modern medicine has at its roots a triumph of rationalism: the emphasis on the search for basic mechanisms of disease and the development of therapeutic tools derived from them. At the turn of the last century, what we think of as modern medicine was understood as allopathic medicine. It was one of a variety of "sects," which included homeopathy, osteopathy, and herbalism. Despite the clinical breakthroughs in anesthesia, antisepsis/asepsis, bacteriology, and pathology, allopathic medicine was by no means the most significant of the sects. Indeed, the homeopathic tradition was in the ascendancy, having many medical schools and taking care of the elite.

A key event in the development of medicine in the United States was the publication of the Flexner report. ${ }^{11}$ Abraham Flexner was a representative of the Carnegie Foundation, whose major interest was in promoting the development of the modern university. As part of that effort, Flexner was commissioned to study the structure and function of medical education. Over four years, he visited all 152 medical colleges in the United States and summarized his findings in what has come to be known as the Flexner report. That report, with the public and private outrage that accompanied it, transformed American medicine. Within thirty years, over half of the medical schools in the United States closed, and those that remained, while heterogenous, were much closer to the Flexnerian model: substantial emphasis on basic science, integrated into the university structure, and having a close affiliation with a teaching hospital.

Flexner understood himself to be writing about the structure of modern medical schools. ${ }^{12}$ For our purposes, however, Flexner's report is valuable because it provides a window on the thinking about rationalism and empiricism at the time of the founding of modern medicine. Flexner was contemptuous of the practitioners of his day, whom he saw almost as mere empiricists, giving out medications by rote in response to symptoms. Describing the education system he wanted to destroy, Flexner observed:

The student's part was, parrot like, to absorb. His medical education consisted largely in getting by heart a prearranged system of correspondences,- - an array of symptoms so set off against a parallel array of doses that, if he noticed the one, he had only to write down the other: a coated tongue-a course of calomel; a shivery back-a round quinine.

11. See Abraham Flexner, Medical Education in the United States and Canada: A REPORT TO THE CARNEGIE FOUNDATION FOR THE ADVANCEMENT OF TEACHING (1960).

12. See id.

13. Id. at 21 . 
Surveying the achievements of Robert Koch, Robert Lister, and particularly the new Johns Hopkins Medical School, Flexner's vision was that the modern physician should be a scientist, trained in the habits and discipline of the basic sciences of anatomy, physiology, pathology, and microbiology. ${ }^{14}$ He compared the clinician to the researcher explicitly:

The main intellectual tool of the investigator is the working hypothesis, or theory, as it is more commonly called. The scientist is confronted by a definite situation; he observes it for the purpose of taking in all the facts. These suggest to him a line of action. He constructs a hypothesis, as we say. Upon this he acts, and the practical outcome of this procedure refutes, confirms, or modifies his theory. Between theory and fact, his mind flies like a shuttle; and theory is helpful and important just to the degree in which it enables him to understand and relate, and control phenomena. This is essentially the technique of research: wherein it is irrelevant to bedside practice? The physician, too, is confronted by a definite situation. He must needs seize its details, and only by powers of observation trained in actual experimentation will enable him to do so. The patient's history, conditions and symptoms form his data. The progress of science and the scientific practice of medicine employ, therefore, exactly the same technique.

At the heart of the modern medical school is the investigation of the basic mechanisms of disease. Flexner argued that having faculty doing research is absolutely critical to the new medical school because the researcher's constant attention to the fundamental mechanisms of disease provides the right milieu for physicians in training. While practicing physicians must, as a matter of practicality, spend their time taking care of patients and cannot focus on research, their temper and temperament have been formed by teachers who are honed at the edge of basic science. Flexner created a temple of medicine, in which the high priests are scientists who illuminate the basic processes of disease. While it is important not to oversimplify Flexner's views - the way of thinking he embraced emphasized the importance of fitting facts to theories-his was a triumph of rationalism over empiricism.

Flexner's vision has been profoundly amplified by the changes in science as mechanisms of disease have moved farther from the bedside, and in the financing of medical schools as external support for research has skyrocketed since World War II. The orthodoxy of modern medicine is rationalist; a large majority of physicians within academic medical centers and in practice are subspecialists who are experts in a particular set of diseases and focus on particular organ systems or diseases. Mechanisms of disease dominate medical school curriculum, as well as much of clinical training.

IV

\section{ClinicAl EPIDEMiology AND the Rise of EVIDENCE-BASED MEDicine}

The rise of clinical epidemiology in the latter half of the twentieth century represented the empiricists' response to the rationalists. The traditional roots of epidemiology were the Hippocratic emphasis on the distribution of disease in

14. See id. at 55.

15. Id. 
space and time and the empiricist tradition. In 1946, John Paul argued for the application of epidemiology to clinical problems. ${ }^{16}$ This approach was elaborated by David Sackett at McMaster, Alvan Feinstein at Yale, and others in the 1960s and 1970s in a series of books and articles. ${ }^{17}$ Arguing that clinical epidemiology is "the basic science of clinical medicine," ${ }^{18}$ Sackett and others took the general approaches of epidemiology-defining a population and assessing exposures-and addressed them to the fundamental clinical questions of causation, therapy, diagnosis, and prognosis. The focus on clinical questions underscored the importance of studies with humans and emphasized patient-centered outcomes. Moreover, use of epidemiologic methods allowed standardized assessment ("critical appraisal") of the strength of study designs. The movement has had different names in different decades and with different audiences: Critical Appraisal of the Literature, Outcomes Research, Practice Guidelines, and Evidence-Based Medicine. ${ }^{19}$

In the 1990s, the term "Evidence-Based Medicine" ("EBM") began to be used to label this general area of work. Sackett defines EBM as "the conscientious, explicit and judicious use of best current evidence in making decisions about the care of individual patients." ${ }^{20}$ What constitutes evidence is in the mind of the beholder, but the territory Sackett claimed included studies on humans that include patient-centered outcomes. ${ }^{21}$ While EBM has had many different expressions, a common approach has been to summarize the available literature around specific questions of clinical management. It is common for techniques of meta-analysis, the statistical combination of similar trials, to achieve a more precise estimate of effect.

A good example of EBM is the approach taken by David C. Slawson and Allen F. Shaughnessey to review the available clinical literature for practicing clinicians. ${ }^{22}$ Writing about the challenges faced by practicing physicians as they try to keep up to date, they distinguish between POEMs and DOEs. ${ }^{23}$ POEM stands for "Patient Oriented Evidence that Matters," meaning methodologically

16. J.R. Paul, Clinical Epidemiology, 17 J. CliniCAL InVESTIGATION 539, 539-41 (1938).

17. See, e.g., Alvan R. Feinstein, Clinical Epidemiology: the Architecture of Clinical Research (1985); Robert H. Fletcher et Al., Clinical EPIDemiology: The EsSentials (1996); DAVID L. SACKetT, CliniCAL EPIDEMIOlOGY: A BASIC SCIENCE FOR CliniCAL MEDiCine (1985).

18. SACKETT, supra note 17 , at ix-xii.

19. The phrase "critical appraisal of the medical literature" was popularized by Sackett and others at McMaster. See Warren Newton, Critical Appraisal of the Medical Literature, in INTRODUCTION TO CliniCAL SkiLls 335 (Mark B. Mengel \& Scott A. Fields eds., 1997). "Practice Guidelines" are attempts to summarize the best available evidence around specific clinical issues. See U.S. DEP'T OF Health \& Human Services, Public Health Service, Agency for Health Care Policy and RESEARCH, PUB. NO. 93-0550 (Apr. 1993). Outcome research is a more general term referring to health services research that focuses on significant patient outcomes.

20. David L. Sackett, Evidence-Based Medicine, 23 SPINE 1085, 1085 (1998).

21. See id.

22. See Allen F. Shaughnessy et al., Becoming an Information Master: A Guidebook to the Medical Information Jungle, 39 J. FAM. PRAC. 489 (1994); David C. Slawson et al., Becoming a Medical Information Master: Feeling Good About Not Knowing Everything, 38 J. FAM. PRACT. 505 (1994).

23. See Shaughnessy et al., supra note 22; Slawson et al., supra note 22. 
strong studies that apply to patients with symptoms similar to the physician's patients and change practice. DOE stands for "Disease Oriented Evidence," or evidence that relates to the pathophysiology of disease, or uses biochemical markers as outcomes. Practicing physicians should search for POEMs and use DOEs only when there is nothing better. The critique of traditional biomedical medical research is radical: The vast majority of published medical work falls into the category of DOEs. ${ }^{24}$ This approach has been incorporated into a series of magazines and new products for practicing clinicians, and its significance has been likened to Dolly the sheep by the editors of the British Medical Journal. ${ }^{25}$

The reaction provoked by EBM has been sharp, as one would anticipate from its impiety and antagonism to clinical experts. The tenor of the discussion can be seen in this comment by a British clinician:

The rise of Evidence Based Medicine has been one of the more remarkable phenomena of the British health scene during the 1990's .... The "fall" of EBM is rather different; since it involves a quasi-theological "fall from grace": a loss of clinical, scientific and educational integrity, even to the point of decline into a "state of sin" (if seeking and clinging to power at any cost is seen as sinful). The moral decline would - in the normal course of events-be followed in due course by loss of status, income and power. However, the EBM barnacle may prove difficult to dislodge now [sic] it has a grip on the minds of politicians and managers. ${ }^{26}$

For the purposes of this argument, the emphasis on EBM represents a renaissance of empiricist thinking cast into modern language. The key questions of epidemiology_accounting for bias and chance-represent a modern treatment, with modern analytic tools, of the empiricists' central question: How does one learn from experience? How does one separate out the role of bias and chance? What is going on in medicine now is a war of cultures between those for whom the mechanisms of disease constitute the best kind of evidence and those who think that appropriately analyzed outcomes are critical.

\section{$\mathrm{V}$ \\ MODERN MEDICINE: CAUSATION}

The tension between rationalism and empiricism illuminates many current policy disagreements and private injuries. Most prominent are questions of clinical causation. From the rationalist perspective, the causation of disease begins at the cellular level with small changes that alter development and trigger disease. Historically, as we have seen, the perceived cause of disease was relatively simple (a disbalance of humours). Similarly, our modern understanding of, for example, the development of cancer may have very simple origins (external radiation, for example) followed by complex intermediary events. Moreover, in public discourse, it is not uncommon for patients, their physicians, and public officials to have strong and simple beliefs about specific agents and

24. See, e.g., Slawson et al., supra note 22, at 508-11. (1997).

25. See Robert Winston, The Promise of Cloning for Human Medicine, 314 BRIT. MED. J. 913

26. B.G. Charlton \& A. Miles, The Rise and Fall of EBM, 91 Q. J. MED. 371, 371-74 (1998). 
their impact. By contrast, an empiricist view is that causation is multifactorial and may be different in different settings. ${ }^{27}$ This difference in understanding of causality is at the root of many of the disagreements about causation in both policy and private injury.

The controversy around silicone breast implants provides an example of how this tension plays out in public discourse. For many years, there has been some concern that silicone exposure may cause autoimmune diseases, especially systemic sclerosis. Silicone is used in many different ways. The administration of drugs and parenteral fluids, as well as dialysis and cardiac bypass, depends on liquid silicone. But the highest profile use is in silicone breast implants for women who require reconstruction after breast cancer surgery or for cosmetic reasons. The question of causation has become very controversial, fired by litigation as well as scientific dissent. ${ }^{28}$

The judge overseeing discovery in all federal cases involving silicone-gelfilled breast implants appointed a neutral group of experts to review the evidence formally. ${ }^{29}$ This group, led by Dr. Barbara Hulka at the University of North Carolina, did a formal meta-analysis of studies of the relationship between breast implants and autoimmune disease. ${ }^{30}$ They found no association between silicone breast implants and a variety of different autoimmune diseases, with summary odds ratio of .69 (95\% CI: .62-.78). ${ }^{31}$ Indeed, because the analysis resulted in an odds ratio significantly less than one, the results suggest that silicone breast implants may protect against autoimmune diseases. Furthermore, using standard techniques for evaluating the impact of the exposure on the population, they concluded that breast implants have minimal effect on women developing connective tissue disorders. ${ }^{32}$ Providing an overview of the controversy, Marcia Angell, the editor of the New England Journal of Medicine, asked the rhetorical question, "when will science prevail?" ${ }^{33}$ The science she defended was that of the empiricists.

27. See Kenneth Rothman, Modern Epidemiology 10-16 (1st ed. 1986).

28. Illustrative breast implant cases include Allison v. McGhan Medical Corp., 184 F. 3d 1300 (11th Cir. 1999), Hall v. Baxter Healthcare Corp., 947 F. Supp. 1387 (D. Ore. 1996), In re Breast Implant Cases, 942 F. Supp. 958 (E. \& S.D.N.Y. 1996).

29. See In re Silicon Breast Implants Prods. Liab. Litig., 793 F. Supp. 1098 (J.P.M.L. 1992).

30. See Esther C. Janowsky et al., Meta-Analyses of the Relation Between Silicone Breast Implants and the Risk of Connective-Tissue Diseases, 342 NEW ENG. J. MED. 781 (2000).

31. Odds ratio compares the odds of a person in one group getting a disease or experiencing a particular outcome with the same odds for a person in another group. "For instance, if $10 \%$ of all people exposed to chemical develop a disease, compared with $5 \%$ of people who are not exposed, the odds of the disease in the exposed groups are 10/90 $=1 / 91$ compared with 5/95 =1/19 in the overexposed group. The odds ratio is 19/9 = 2.1." David H. Kaye \& David A. Freedman, Reference Guide on Statistics, in REFERENCE MANUAL On SCIENTIFIC EVIDENCE 83, 167 (Federal Judicial Ctr. ed., 2d ed. 2000). A summary odds ratio aggregates several individual studies.

32. See Janowsky et al., supra note 30 , at 781 .

33. Marcia Angell, Breast Implants: Protection or Paternalism?, 326 NEW ENG. J. MED. 1695 (1992). 
Scientific reaction has been sharp. The first letter published in response to the study, written by Eugene Goldberg, took up the issue of what kind of science was being used:

\begin{abstract}
As an educator and academic biomedical scientist, I found the lengthy special article ... to be inconsistent with the scientific standards we have come to expect from the journals .... [I]ts credibility is lost because of total disregard of a substantial body of scientifically sound data on the extraordinary rate of implant failure (now estimated to involve rupture and gross leakage of silicone in 50 percent of cases after approximately eight years), the substantial degradation of the silicone shell and gel with time, the pain and disfigurement that result from contraction of the fibrous capsule, the chronic inflammation due to immune-system responses involving phagocytosis of fine silicone droplets by macrophages and giant cells and the spread of silicone throughout the body. ${ }^{34}$
\end{abstract}

At issue is what kind of science is used to address causation. What Angell defines as science is modern epidemiology, a careful examination of a variety of studies of the association between exposure and disease in different settings. Some of the published commentary quarrels with the epidemiological methods used by Hulka and her colleagues; such commentary shares a focus on patient outcomes with Hulka and is a very familiar part of the empiricist tradition. By contrast, what Goldberg construes as science are the modern biomedical sciences. Each argument he gives is a possible mechanism of disease.

\title{
VI
}

\section{MODERN MEDICINE: THERAPY}

One of the major contributions of clinical epidemiology has been the understanding that causation is only one of the fundamental clinical questions. Of the other clinical questions, therapy comes up most frequently as an issue for discussion. The usual question is: Which specific therapy is more efficacious? In practice, there are often answers provided by an understanding of mechanisms of disease that differ from those suggested by the results of clinical trials.

The example of calcium channel blockers in the setting of myocardial ischemia discussed in the introduction is one of these controversies. Other examples are common: first-line pharmacotherapy for depression (Serotonin Reuptake Inhibitors vs. Tricyclics), and treatment of patients with chronic lung disease (Albuterol vs. Ipratropium). Each of these examples shares the widespread use of a medication because of the plausibility of its biological mechanism in the absence of - or in spite of-empirical studies of its effect on outcomes that matter to patients, such as survival, quality of life, functional status, or satisfaction with care.

\section{A. Clinical Policies}

Decisions about therapy often have implications beyond individual patients, because many emerging therapies have vast implications for the public and for

34. Eugene P. Goldberg, Evaluating the Health Risks of Breast Implants, 335 NEW ENG. J. MED. 1154, 1154 (1996). 
the organization of health care delivery systems. An example is thrombolysis for strokes. For approximately fifteen years, a common treatment strategy for acute myocardial infarction has been to give drugs that dissolve the clots inside of the coronary vessels that precipitate myocardial infarction. This strategy, termed thrombolysis, has turned out to be useful in preserving myocardium, at least temporarily. Extending this thinking to the brain and to strokes, a number of centers have been exploring the acute treatment of "brain attacks," a common term for marketing this approach to the public. ${ }^{35}$

The argument in favor of thrombolysis rests on pathophysiological reasoning. Many strokes are caused by clots in the blood vessels leading to the brain; the clot stops blood supply to a part of the brain; without oxygen, that part of the brain is irreversibly damaged. Medications that alter the humours-in this case, dissolve the clot-offer the possibility of preventing irreversible damage to parts of the brain if given quickly. From an empiricist view, the key issue is whether such agents actually work: Are strokes "prevented" or limited in size such that functional status, quality of life, and survival are improved?

The stakes are large. The medication is very expensive- $\$ 1200$ to $\$ 1300$ per dose-and as this becomes the standard of care, it will mean extensive public awareness campaigns and dramatic changes in our emergency medical transport system. A single large trial has added substantial impetus to this change in clinical policy. ${ }^{36}$ Six hundred twenty-four subjects with symptoms for less than three hours were randomized to TPA, a clot dissolving agent, or to a placebo. Patients receiving TPA had increased numbers of intracranial hemorrhages, but, despite that, a trend to better survival and significantly better function at three months by four different functional measures. ${ }^{37}$ The number of patients that needed treating to have one patient do substantially better was $8-11$, an important and impressive result. ${ }^{38}$

Unfortunately, the picture is not so simple, despite the enthusiasm around the trials. Table 1 summarizes the other major randomized clinical trials of thrombolysis for strokes, with numbers of patients, drug, duration of symptoms, and outcomes. The other clinical studies are different in important ways (drug chosen, timing of medication) but are impressive for their poor outcomes. ${ }^{39}$ Moreover, clinical experience with thrombolysis has underscored a variety of important preclinical issues in addition to efficacy. Almost all patients do not

35. See National Inst. of Neurological Disorders, Stroke rt-PA Stroke Study Group, Tissue Plasminogen Activator for Acute Ischemic Stroke, 333 NEW ENG. J. MED. 1581 (1995).

36. See id.

37. See id.

38. See id.

39. See G.A. Donnan et al., Trials of Streptokinase in Severe Acute Ischaemic Stroke, 345 LANCET 578 (1995); European Cooperative Acute Stroke Study, Intravenous Thrombolysis with Recombinant Tissue Plasminogen Activator for Acute Hemispheric Stroke, 274 JAMA 1017 (1995); Multicentre Acute Stroke Trial-Italy (MAST-1) Group, Randomised Controlled Trial of Streptokinase, Aspirin, and Combination of Both in Treatment of Acute Ischaemic Stroke, 346 LANCET 1509 (1995); Multicentre Acute Stroke Trial-Europe Study Group, Thrombolytic Therapy with Streptokinase in Acute Ischaemic Stroke, 274 JAMA 1017 (1995). 
arrive within the critical three-hour window; in one trial, despite a substantial community awareness program, less than one percent of patients with strokes were captured. ${ }^{40}$ Moreover, for patients who do arrive in time, the exclusion of hemorrhagic stroke-which is necessary before thrombolytics can be given safely - is error prone, even when performed by experienced academic physicians. $^{41}$

The case of thrombolysis illustrates how the tension between mechanisms of disease and empiricism plays out in consideration of a new generation of treatment in our society. The animus for the intervention comes from understanding the mechanism of disease; the idea gains support from investigators, academic medical centers, and industry, supporting a major federal trial-a concession to the value of empiricism. With a single positive trial, and with extensive publicity, this treatment is becoming the standard of care, despite many concerns about efficacy and overall effectiveness. ${ }^{42}$ As adverse events occur, there will be ample documentation of the dangerousness and lack of practicality of the drugs.

TABLE 1:

THROMBOLYSIS FOR STROKES

\begin{tabular}{lllll}
\hline Study & N & Drug & Time & Outcome \\
\hline MASTI & 622 & Streptokinase & 6 hours & kills \\
MASTE & 310 & Streptokinase & 6 hours & kills \\
ASK & 340 & Streptokinase & 4 hours & kills/maims \\
ECASS & 620 & TPA & 6 hours & kills, but... \\
\hline
\end{tabular}

B. How to Choose Optimal Therapy for an Individual Patient

Often the appropriate choice of therapy for an individual patient is at issue. Clinicians with a traditional perspective emphasize the importance of using what is known about pathophysiology to make decisions about therapy. So, for a patient in an intensive care unit setting, discussion of the physiology of the patient is the necessary preface for deciding on treatment. In contrast, enthusiasts of Evidence-Based Medicine argue that the best estimate of an individual response to therapy is the average response of a group to that therapy.

40. See P.B. Fontanarosa \& M.A. Winker, Timely and Appropriate Treatment of Acute Stroke, 279 JAMA 1307 (1998).

41. See D.L. Schriger et al., Cranial Computed Tomography Interpretation in Acute Stroke, 279 JAMA 1293 (1998).

42. In clinical epidemiology, there is an important distinction between efficacy-whether a treatment will work under ideal conditions of a funded clinical trial, with highly selected clinicians and patients, financial incentives for both clinicians and patients, free treatment and medical and support staff to monitor patients-and effectiveness - whether a treatment will work in usual conditions, with usual clinicians and patients and no special reimbursement or monitoring. 
Both viewpoints have their limits. Our understanding of pathophysiology in individual cases is often limited and provides a shaky basis for therapy that improves long-term patient outcomes. So, too, is what evidence-based practice can say. As Alvan Feinstein has underscored, ${ }^{43}$ for many clinical problems, no available high quality clinical information (such as randomized controlled trials) is available. Generalizing information from subgroup analyses of clinical trials is fraught with potential error, and the amount of work necessary to have continually updated information poses a further practical barrier.

\section{VII}

\section{MODERN MEDICINE: DiAgNOSIS}

\section{A. Pattern Recognition versus Bayesian Analysis}

The remaining fundamental clinical questions-diagnosis and prognosisare not a primary focus of either the rationalist or the empiricist traditions. Nevertheless, the tension between the traditions persists in current clinical care and its associated litigation. The classic mode of diagnosis of a traditional rationalist approach is of pattern recognition - the recognition of the signs and symptoms that are external manifestations of an inner disease whose cause is known. Thus, Hippocrates emphasized key features of particular diseases, such as malaria with a fever every three days. ${ }^{44}$ An excellent modern statement of this is by Nicholas A. Vick in one of the major textbooks of neurology. ${ }^{45}$ Vick explains that

a complete and thorough neurological examination may be fitted together like a jigsaw puzzle .... [T] he symptoms described by the patient ... suggest disease of certain structure, whose function then should be tested thoroughly with more exact methods .... [A]n understanding of clinical neurology cannot be reached merely by memorizing signs and symptoms of diseases. ${ }^{46}$

By contrast, diagnostic reasoning in many clinical settings is probabilistic or Bayesian $^{47}$ and reflects the impact of context or prevalence of disease in a particular setting. An excellent example is the performance of diagnostic tests in different populations. One of the best diagnostic tests available in clinical medicine is the diagnostic test for HIV, which has sensitivity and specificity well above ninety-five percent. Yet the performance of that diagnostic test is dramatically dependent on the prevalence of the disease in the population being tested. Thus, a positive test in the Castro district of San Francisco (which has a

43. See Alvan R. Feinstein \& Ralph I. Horwitz, Problems in Evidence of Evidence-Based Medicine, 103 AM. J. MED. 529, 531-32 (1997).

44. See generally MAJOR, supra note 4, at 115-38.

45. See Nicholas A. Vick, GrinKeR's NeUROlOGy (7th ed. 1976).

46. Id. at 4 .

47. In Bayesian statistics (sometimes called subjectivist statistics), an investigator assigns a subjective "prior" probability to a hypothesis. The application of Bayes' rule (or theorem) to collected data permits the computation of a "posterior" probability that expresses the investigator's belief about the validity of the hypothesis. See Kaye \& Freedman, supra note 31, at 152-53, 160. 
high prevalence of HIV) is almost always a true positive. The positive predictive value is almost $100 \%$. If one gets a positive test, one can be comfortable describing the test as "almost definite." However, in a positive for a patient in a rural area of North Carolina with a much lower prevalence of HIV, the likelihood of a false positive test is much higher-as high as fifty percent or sixty percent, depending on the population. The test is the same, but it performs differently in different populations.

The contrast is between the two modes of diagnosis. One-pattern recognition-hearkens back to a rationalist ancestry that emphasized a single cause for a disease; it is a single-step process and is independent of location. The other, which comes out of empiricist lineage with its modern mathematical framework, is dependent on context. The difference between these perspectives at the clinical point of service animates many disagreements among clinicians, expert witnesses, and policymakers. ${ }^{48}$

\section{B. Early Diagnosis of Disease: Screening for Breast Cancer in Women between Forty and Fifty}

Controversies over routine screening provide an example of how different approaches to evidence combined with politics lead to dramatic differences in recommendations by different expert bodies. For more than a generation, the American Cancer Society ("ACS") has promoted early screening for all types of cancer. ${ }^{49}$ Relying on informal expert panel advice, they have developed and maintained a set of recommendations for screening. ${ }^{50}$ The general approach is screen early, screen often, screen as much as possible. The unifying theory is based on an understanding of the pathology of cancer: Cancers spread; earlier cancer has spread, and cure is more likely if the cancer is treated before it spreads widely. For breast cancer, this has translated to a recommendation for screening for all women starting at thirty-five. ${ }^{51}$

In contrast, from the empiricist perspective, a number of organizations have attempted over the last twenty-five years to make recommendations for prevention based on what clinical trials show about the outcomes of screening. Building on the work of the Canadian Task Force on the Periodic Exam and the work of Paul Frame, the United States Preventive Services Task Force ("USPSTF") has set explicit criteria for reviewing clinical preventive services. ${ }^{52}$ These criteria include the burden of suffering, the characteristics of the test (sensitivity, specificity, and side effects) and particularly the evidence about ef-

48. Disagreements about the use and value of specific diagnostic tests or maneuvers are common. An excellent introduction to this issue, along with many clinical examples, is found in SACKETT, supra note 17 , at 3-155.

49. For the American Cancer Society's recommendations for screening, see <http.www.cancer. org $>$ (visited May 2, 2001).

50. See id.

51. See id.

52. See U.S. Preventive Services Task Force, Guide to Clinical Preventive Services (2d ed. 1996). 
fectiveness, that is, the impact on morbidity or mortality as shown in clinical studies. For screening for breast cancer in women between forty and fifty, the results of clinical trials have been mixed, with at least one major properly performed trial showing no benefit of screening. ${ }^{53}$ As a consequence, the last edition of the USPTF gave screening for breast cancer between forty and fifty years a "C" grade, meaning no good evidence supports routine screening. ${ }^{54}$ While this specific recommendation may change as the result of recent data reporting longer follow-up periods, the population impact of screening for fortyto fifty-year-olds is so small that support for routine screening will be tepid, emphasizing informed consent of the patient's role in the process.

In summary, both the process and the specific recommendations of the ACS and the USPSTF are very different, and the controversy about recommendations for breast cancer screening for women between forty and fifty has been noisy. ${ }^{55}$ The controversy reflects different underlying approaches to evidence - rationalist and empiricist—amplified by the emotional and political salience of the disease.

\section{VIII}

\section{Modern MEdicine: Prognosis}

The tension between rationalism and empiricism also informs how modern medicine addresses prognosis. Along with causation, therapy, and diagnosis, prognosis is one of the fundamental questions of clinical medicine; without knowledge of prognosis, or the natural history of disease, it is difficult to know whether and how to treat. The rationalist worldview, however, has as its primary focus the causation of disease. What happens next, in terms of the progression of symptoms and morbidity or mortality, is of secondary importance. By contrast, the empiricist tradition has always been much more attentive to the particularities of the natural history of disease.

The dominance of the rationalist worldview, together with an American insistence on cure as quickly as possible, is reflected in the published medical literature and its lack of attention to prognosis. Working with colleagues, I reviewed all the articles with pneumonia as a Medical Subject Heading term in an entire year. We chose pneumonia because it is very common and remains one of the top contributors to mortality for people over sixty-five years old. We re-

53. See A.B. Miller et al., Canadian National Breast Screening Study: Breast Cancer Detection and Death Rates Among Women Aged 40-49 Years, 147 CAN. MED. Assoc. J. 1459, 1459-76 (1992).

54. See id.

55. The controversy involved the leadership of the National Cancer Institute. A good introduction to the science of the controversy is a set of articles in Annals of Internal Medicine. See Russell Harris \& Linda Leininger, Clinical Strategies for Breast Cancer Screening: Weighing and Using the Evidence, 122 AnNAls InTERnAl Med. 539 (1995); Edward A. Sickles \& Daniel B. Kopanos, Mammographic Screening for Women Aged 40-49 Years of Age: The Primary Care Practitioner's Dilemma, 122 ANNALS INTERNAL MED. 534 (1995). 
viewed a total of 1147 articles; as Figure 2 depicts, articles on prognosis were rare and significantly less common than articles on treatment. ${ }^{56}$

The inattention to prognosis is more fundamental than the lack of research attention; it also relates to the inexact linkage between diagnosis and prognosis. As Alvan Feinstein has argued, ideally diagnostic terminology should include some component of prognosis. For example, there should be a strong linkage between the stage of a cancer and the prognosis. A stage I cancer should live longer than stage II, and so on. Often, however, our staging mechanisms are based in our understanding of pathology-the spread of the cancer through specific tissues-rather than prognosis. ${ }^{57}$ For cancers, this has often taken the form of staging systems that describe the size of the tumors, involvement of lymph nodes, and the presence of metastases. This is the so-called TNM system, and, for many cancers, several TNM classes are grouped into stages (A-D or I-IV).

For Feinstein, the prognostic implications of diagnosis are critical, and he has described an alternate classification system based on symptoms and comorbidity as well as pathology, with an emphasis on features that were easily apparent to the physician, such as the presence of such specific symptoms as pain or anorexia, and co-morbidity such as heart failure. ${ }^{58}$ Feinstein has described this alternate kind of system with a wide variety of diseases. ${ }^{59}$ Table 2 compares the performance of his system against the traditional approach to staging for cancer of the larynx. The Feinstein system predicts survival much better; the table underscores the prognostic variation within traditional disease classification.

From the perspective of the argument of this paper, prognosis is not fundamentally important to the rationalist vision, and the classification systems based on mechanisms of disease address it only imperfectly. This case (and many others) shows the dramatic improvement in power by inclusion of the relatively simple information within the grasp of the practitioner. It is a measure of the strength of the rationalist worldview in current clinical medicine that classification systems have not changed markedly.

The renaissance of empiricism has led to a return of an emphasis on prognosis in the organization of clinical care. An excellent example is the development of clinical care pathways based on prognosis. These have spread through hospitals over the last ten years as a way of standardizing and improving the quality of care. The management of chest pain provides an example. Traditionally, the hospital evaluation of chest pain was focused on diagnosis-whether there had been a myocardial infarction. This assessment was based on a combination of cardiac enzymes, the electrocardiogram, and the clinical setting-the recogni-

56. See Figure 2 in the Appendix.

57. See Alvan Feinstein, Cancer of the Larynx: A New Staging System and a Re-Appraisal of Prognosis and Treatment, 30 J. CHRONIC DISEASES 277 (1977).

58. See id.

59. See id. 
tion of the disbalance of the humours. Over the last five years, a major new approach to diagnosing myocardial infarctions has been described and evaluated - the use of Troponins. This new test was justified by its link to prognosis. ${ }^{60}$ Moreover, most new clinical pathways for chest pain have prognosis as their central organizing principle, focusing on separating out low-risk individuals from high-risk, not directly related to the presence or absence of myocardial infarction. This approach is being applied in a large range of clinical settings, from febrile infants to the frail elderly.

TABLE 2

COMPARISON OF STAGING SYSTEMS FOR CANCER OF LARYNX (\% 5-YEAR SURVIVAL)

\begin{tabular}{lccccc}
\hline $\begin{array}{l}\text { Composite } \\
\text { S-A-C } \\
\text { Stages }\end{array}$ & I & II & III & IV & Total \\
\hline Alpha & $85 \%$ & $100 \%$ & $100 \%$ & - & $88 \%$ \\
Beta & $64 \%$ & $100 \%$ & $42 \%$ & - & $60 \%$ \\
Gamma & $63 \%$ & $50 \%$ & $36 \%$ & - & $44 \%$ \\
Delta & $22 \%$ & $100 \%$ & $17 \%$ & $8 \%$ & $15 \%$ \\
Total & $67 \%$ & $82 \%$ & $36 \%$ & $8 \%$ & $50 \%$ \\
\hline Soustered TNM stages
\end{tabular}

Source: Alvan Feinstein, Cancer of the Larynx: A New Staging System and a Re-Appraisal of Prognosis and Treatment, 30 J. CHRONIC DisEASES 277, 277-305 (1977).

IX

\section{CONCLUSION}

There is an important difference in ways of thinking between empiricists and rationalists. This tension was present in its most stark form in ancient times with the often-bitter clash of rationalists and empiricists. At its founding, modern medicine represented a triumphal return of the rationalists. Their insistence on understanding the mechanisms of disease has been architectonic for modern clinical medicine. For all its rhetoric of novelty, Evidence Based Medicine represents a counter-revolution of traditional empiricism, draped in modern clothes of statistics and multi-variate analysis. The tension between rationalism and empiricism abides and finds its expression in a wide variety of clinical questions. The culture war within medicine starts with causation and extends to

60. For an example of a pathway based on prognosis, see Christian Hamm et al., Emergency Room Triage of Patients with Acute Chest Pain by Means of Rapid Testing for Cardiac Troponin T or Troponin I, 337 New Eng. J. Med. 1648 (1997). See also Agency FOR HEAlth CARe Policy AND Research, National HeArt, Lung, and Blood Institute, Unstable Angina: Diagnosis AND MANAGEMENT ClinicAl PRACTICE GuidELINE No. 10 (1994). 
the other fundamental clinical questions-diagnosis, prognosis, and treatmentwhich are at the center of clinical disagreements, private injuries, and policy debates. 
APPENDIX

FIGURE 1:

INDICATIONS FOR DILTIAZEM (AUGUST 1991)

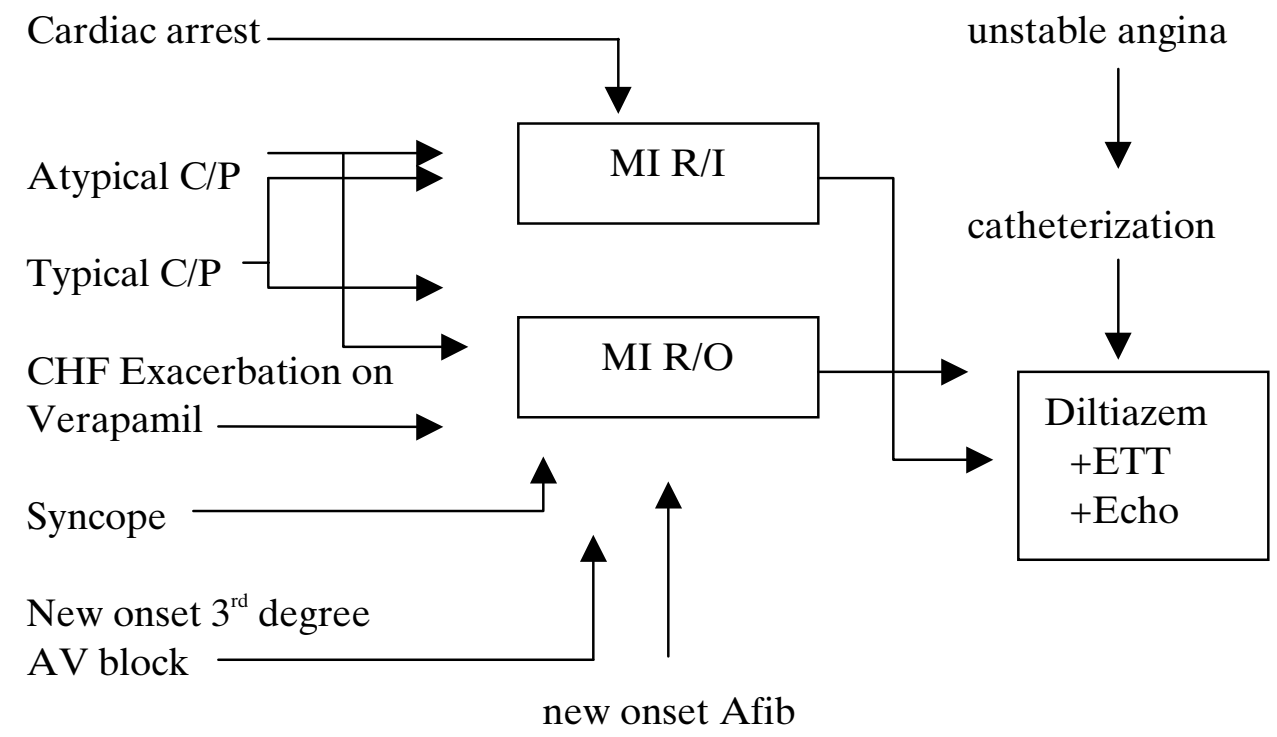

FIGURE 2:

PROGNOSIS IN THE LITERATURE

\begin{tabular}{|c|c|}
\hline Pneumonia & $\begin{array}{l}\text { Diagnosis } \\
\text { 圆Treatment } \\
\text { 口Prognosis } \\
\text { OPrevention } \\
\text { 目Causation } \\
\square \text { Practice observed } \\
\square \text { Review } \\
\square \text { Case reports }\end{array}$ \\
\hline
\end{tabular}

